\title{
Lidocaine/L-Menthol Binary System: Cocrystallization versus Solid-State Immiscibility
}

\author{
Yohann Corvis, ${ }^{*}, \dagger$ Philippe Négrier, ${ }^{\ddagger}$ Mathieu Lazerges, ${ }^{\dagger}$ Stéphane Massip, ${ }^{\S}$ \\ Jean-Michel Léger, ${ }^{\S}$ and Philippe Espeau
}

Laboratoire Physico-Chimie Industrielle du Médicament, EA 4066, Faculté des Sciences Pharmaceutiques et Biologiques, Université Paris Descartes, 4 Avenue de l'Observatoire, 75270 Paris Cedex 06, France, Centre de Physique Moléculaire Optique et Hertzienne, UMR CNRS 5798, Université de Bordeaux, 351 cours de la Libération, 33405 Talence Cedex, France, and EA 4138 - Pharmacochimie, UFR des Sciences Pharmaceutiques, Université de Bordeaux, 146 rue Léo Saignat, 33076 Bordeaux Cedex, France

\begin{abstract}
We present the synthesis, structure determination, and thermodynamic properties of a never reported cocrystal prepared with lidocaine and L-menthol. The temperature-composition phase diagram of the lidocaine/L-menthol binary system was achieved using differential scanning calorimetry and X-ray diffraction experiments. The present study demonstrates that the only way to perform a phase equilibrium survey of the lidocaine/L-menthol system is to prepare the binary mixtures from the cocrystal, an equimolar stoichiometric compound of L-menthol and lidocaine. We describe a process that is crucial to elaborate pharmaceutical agents that remain in their thermodynamical stable state throughout their preparation, manufacture, and storage for effective use.
\end{abstract}

\section{Introduction}

2-(Diethylamino)- $N$-(2,6-dimethylphenyl)-acetamide, otherwise known as lidocaine, is classified as an amide type anesthetic compound. This drug is usually used for local transdermal application before venipuncture ${ }^{1}$ or minor surgical procedures. ${ }^{2}$ Eutectic mixtures based on lidocaine/excipient association are often prepared for this purpose. ${ }^{3-5}$ The choice of the excipient is crucial to ensure its thermodynamic stability, nontoxicity, and bioavailability. For proper therapeutic use, the eutectic mixture has to remain in the liquid state in a temperature range below room temperature. That is the reason why the active pharmaceutical ingredient (API) and the excipient interactions must be studied in their thermodynamic stable phase. Moreover, the excipient, which can be helpful for a better delivery of the drug through the skin, has to be harmless. EMLA eutectic mixture (AstraZeneca PLC, London, U.K.), with lidocaine and prilocaine as therapeutic agents, has been developed and is widely used, especially in medical care for children. Nevertheless, prilocaine, known as a methemoglobin inducer, displays pathologic issues during the drug metabolism. ${ }^{6,7}$ L-Menthol, a transdermal enhancer agent for API, ${ }^{8}$ is often considered as a suitable excipient for the eutectic preparations using topical anesthesia. ${ }^{9}$ The lidocaine/L-menthol binary mixture has been recently patented ${ }^{10}$ and the corresponding temperature-composition $(T-x)$ phase diagram published by Kang and co-workers. ${ }^{11}$ At first sight, the diagram could indicate a liquid/liquid demixtion around the equimolar binary composition. However, upon further investigation, we discovered that the phase diagram exhibits inconsistencies with respect to the invariant equilibrium. The latter manifest themselves at $\sim 39{ }^{\circ} \mathrm{C}$ and for lidocaine molar ratios around the equimolar composition. We hypothesized that the existence of a stoichiometric compound (cocrystal) ${ }^{12-15}$ at $x=0.5$ could explain the formation of the invariant equilibrium. A schematic

* To whom correspondence should be addressed. E-mail: yohann.corvis@ parisdescartes.fr. Phone: +331537396 80. Fax: +33153739676.

†niversité Paris Descartes.

‡ Centre de Physique Moléculaire Optique et Hertzienne, Université de Bordeaux.

${ }^{\S}$ EA 4138 - Pharmacochimie, Université de Bordeaux.
SCHEME 1: Structure of the Molecular Assembly Proposed to Form in the Lidocaine:L-Menthol Cocrystal ${ }^{a}$

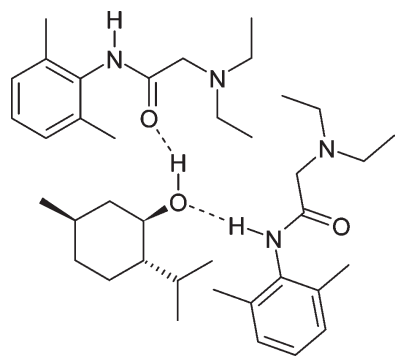

${ }^{a}$ Hydrogen bonds are represented by dashed lines.

representation of a common building block-a three-membered assembly (lidocaine $)_{2} \cdot(\mathrm{L}-\mathrm{menthol})$-within the cocrystal is proposed in Scheme 1. Deeper investigations of the phase diagram were thus carried out in order to check this conjecture. Subsequently, single crystals of a 1:1 stoichiometric compound were obtained. This new compound was characterized by single crystal X-ray diffraction and thermal analysis. Taking into account this compound, the stable $T-x$ phase diagram was established. The metastable phase diagrams were established as well and compared from a thermodynamic point of view with the stable one.

\section{Experimental Section}

Materials. Lidocaine (purity $\geq 98.5 \%$; CAS 137-58-6) and L-menthol (purity: 99.7\%; CAS 2216-51-5) were purchased from Sigma-Aldrich and Acros Organics, respectively. No further purification steps were necessary.

Cocrystal Synthesis. The stoichiometric compound was obtained by melting a mixture of lidocaine and L-menthol in equimolar proportion at $90{ }^{\circ} \mathrm{C}$ in a glass vial. Then, the vial was quenched first at $-80{ }^{\circ} \mathrm{C}$ for $10 \mathrm{~min}$ to obtain a glassy phase, and finally heated from $-80{ }^{\circ} \mathrm{C}$ to room temperature. Spontaneously, crystals of the 1:1 compound (Figure 1) were formed by nucleation during warming of the sample. The vial was sealed in order to avoid L-menthol evaporation during the heating and cooling processes. 


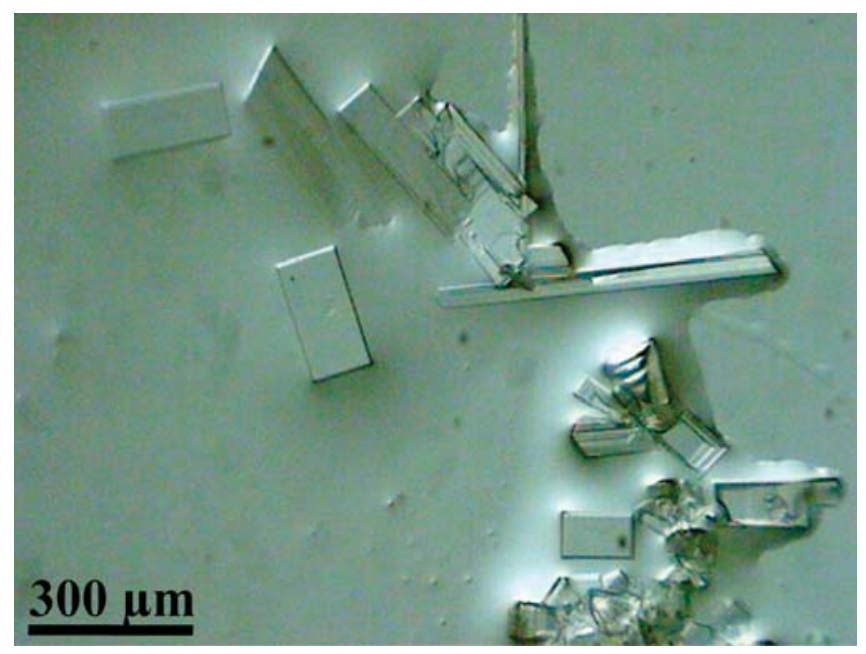

Figure 1. Micrograph of the lidocaine:L-menthol cocrystals immersed in an enriched L-menthol liquid phase.

Sample Preparations for the DSC Runs. The stable $T-x$ phase diagram of lidocaine/L-menthol was established by mechanically mixing in a mortar the stoichiometric compound with lidocaine, or L-menthol, all in their solid state. The 1:1compound/L-menthol mixtures were prepared in a $3{ }^{\circ} \mathrm{C}$ cold room, whereas the 1:1-compound/lidocaine ones were prepared at room temperature. For an optimum equilibrium profile, the lidocaine-rich sealed samples were stored in an oven at $35^{\circ} \mathrm{C}$ after the preparation. After 1 month, the differential scanning calorimetry (DSC) experiments were performed.

The metastable phase diagrams with invariant points at 0.3 and $12.3{ }^{\circ} \mathrm{C}$ were obtained after recrystallization of the molten mixtures by cycling three times from -60 to $-2{ }^{\circ} \mathrm{C}$ at a 10 $\mathrm{K} \cdot \min ^{-1}$ scan rate and by annealing at $-5{ }^{\circ} \mathrm{C}$ for 1 month, respectively.

Single-Crystal X-ray Diffraction. A crystal $(120 \mu \mathrm{m} \times 100$ $\mu \mathrm{m} \times 60 \mu \mathrm{m}$ ) was trapped by a gripper and placed in a nitrogen environment at $234 \mathrm{~K}$. A capillary was inserted between the gripper and the $\mathrm{N}_{2}$ flow in order to protect the crystal. Data were collected with an R-Axis Rapid Rigaku MSC diffractometer using the $\mathrm{Cu} \mathrm{K} \alpha$ radiation and a graphite monochromator. All reflections were used for unit cell refinement. The Mercury 2.2 program was used for analysis and graphic representation. ${ }^{16}$ Other programs such as Materials Studio Modeling 4.1 ${ }^{17}$ and ORTEP-3 $2.02^{18}$ were also used for drawing the molecular graphics. The crystal structure was solved by direct methods Shelx $86^{19}$ and refined using the Shelx $97^{20}$ suite of programs. The positions of the $\mathrm{H}$ atoms were deduced from coordinates of the non-H atoms and confirmed by Fourier synthesis. The non-H atoms were refined with anisotropic temperature parameters. Nonrefined $\mathrm{H}$ atoms were included for structure factor calculations.

Thermal Analysis. Temperatures and enthalpies of fusion were determined using a differential scanning calorimeter (Mettler-Toledo, Switzerland) calibrated beforehand with high purity indium and zinc reference samples. DSC runs were performed at $5 \mathrm{~K} \cdot \mathrm{min}^{-1}$ under an atmosphere of dry nitrogen gas. For more accurate statistics, the experiments on pure compounds (lidocaine, L-menthol) and on the 1:1 compound were reproduced at different scan rates and with different sample weights. No variation of the enthalpy of fusion vs the specific volume of the sample, namely, V/m, ${ }^{21}$ was observed with these three components.
TABLE 1: Crystal Data and Structure Refinement Parameters for the Lidocaine:L-Menthol 1:1 Compound

$\begin{array}{ll}\text { formula } & \mathrm{C}_{24} \mathrm{H}_{42} \mathrm{~N}_{2} \mathrm{O}_{2} \\ \mathrm{FW}\left(\mathrm{g} \cdot \mathrm{mol}^{-1}\right) & 390.60 \\ \text { temperature } & 233 \mathrm{~K} \\ \text { wavelength } & 1.54180 \AA \\ \text { cryst. syst. } & \text { orthorhomb } \\ \text { space group } & \mathrm{P} 2{ }_{1} 22_{1} 2_{1} \\ \text { unit cell dimensions } & \\ \quad a(\AA) & 8.4016(5) \\ \quad b(\AA) & 13.4207(9) \\ \quad c(\AA) & 22.130(2) \\ \text { volume }\left(\AA^{3}\right) & 2495.3(4) \\ Z & 4 \\ D_{x}\left(\mathrm{~g} \cdot \mathrm{cm}^{-3}\right) & 1.040 \\ \mu\left(\mathrm{mm}^{-1}\right) & 0.503 \\ \mathrm{R} 1, I>2 \sigma(\mathrm{I}) & 0.0485 \\ \mathrm{wR} 2, I>2 \sigma(\mathrm{I}) & 0.1151 \\ S & 1.011\end{array}$

\section{Results and Discussion}

1. Characterization of the Cocrystal. The crystal structure of the 1:1 stoichiometric compound was established by single X-ray diffraction (Cambridge Crystallographic Data Centre reference number 753770), and the collected data are presented in Table 1. The lidocaine:L-menthol addition compound crystallizes in a $\mathrm{P} 2{ }_{1} 2_{1} 2_{1}$ orthorhombic space group (Figure 2). The conformation of the corresponding molecules within the crystal is shown in Figure 3. As a reminder, the crystal structures of stable L-menthol ${ }^{22}$ (named the $\alpha$-phase) and lidocaine ${ }^{23}$ have

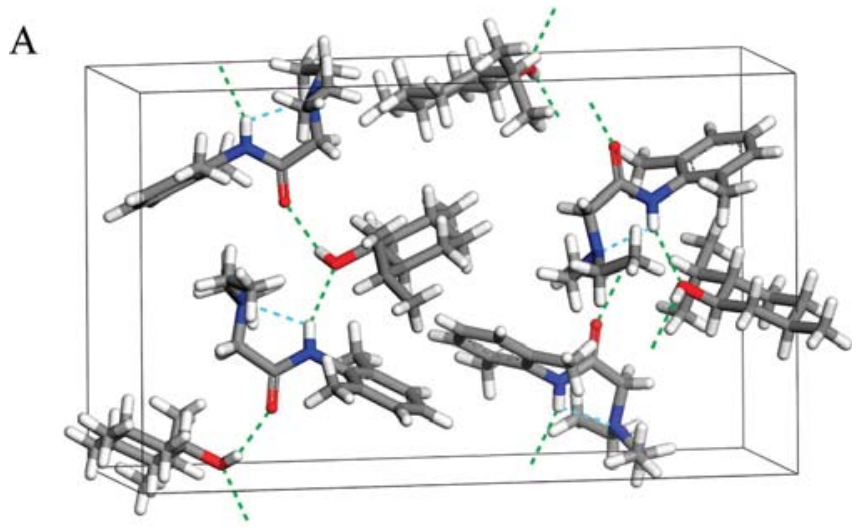

$\mathrm{B}$

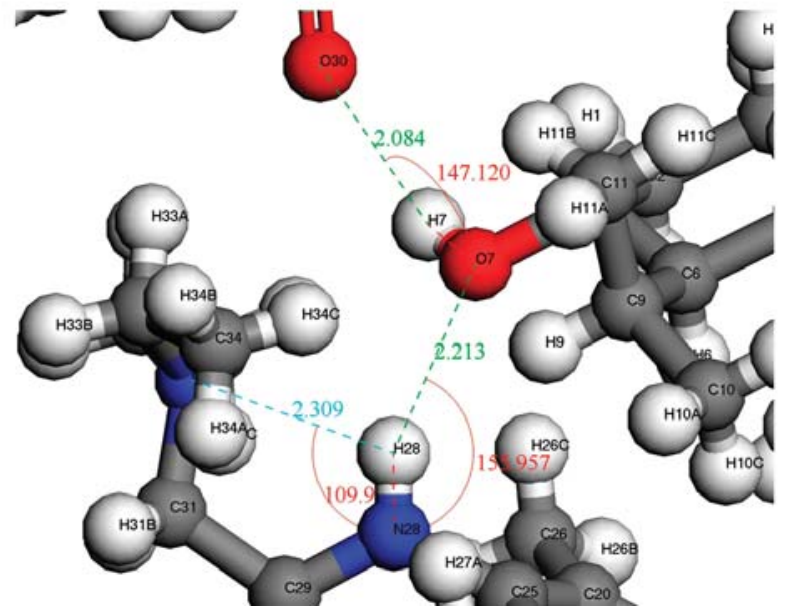

Figure 2. (A) Crystal structure of the lidocaine:L-menthol compound. (B) Geometry of the hydrogen bonds within the cocrystal. Hydrogen bonds are represented by dashed lines. Intra- and intermolecular hydrogen bonds are colored in cyan and green, respectively. 
A

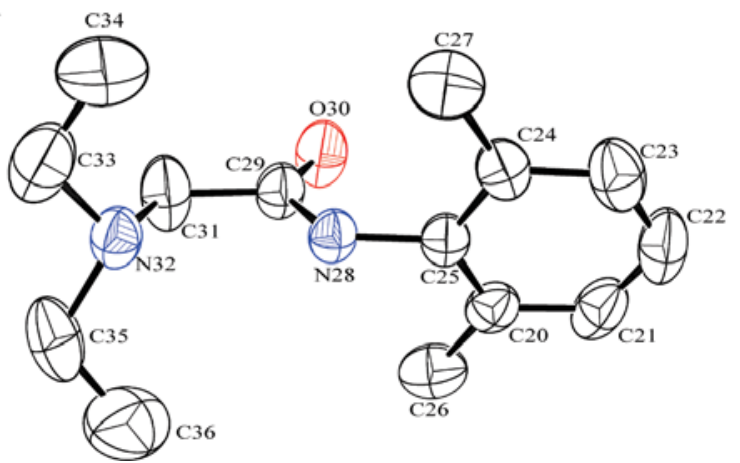

$\mathrm{B}$

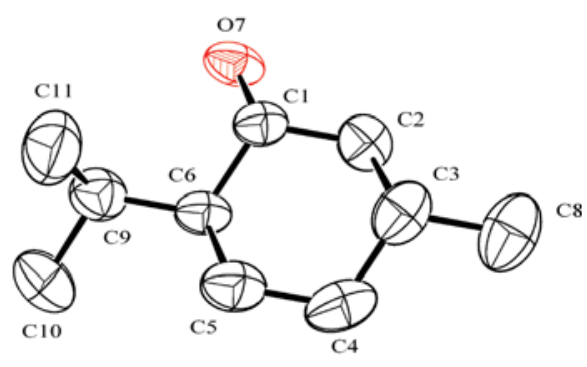

Figure 3. Oak Ridge thermal ellipsoid plot (ORTEP, 50\% probability) of lidocaine (A) and L-menthol (B) within the cocrystal.

TABLE 2: Hydrogen Bond Geometry in the Cocrystal ${ }^{a}$

\begin{tabular}{cccccc}
\hline & & \multicolumn{3}{c}{ length $(\AA)$} & angle (deg) \\
\cline { 3 - 5 } H-bond type & $\mathrm{D}-\mathrm{H} \cdots \mathrm{A}$ & $\mathrm{D}-\mathrm{H}$ & $\mathrm{H} \cdots \mathrm{A}$ & $\mathrm{D} \cdots \mathrm{A}$ & $\mathrm{D}-\mathrm{H} \cdots \mathrm{A}$ \\
\hline intermolecular & $\mathrm{N}-\mathrm{H} \cdots \mathrm{O}$ & 0.870 & 2.213 & 3.029 & 155.96 \\
& $\mathbf{O}-\mathrm{H} \cdots \mathrm{O}$ & 0.830 & 2.084 & 2.818 & 147.12 \\
intramolecular & $\mathrm{N}-\mathrm{H} \cdots \mathrm{N}$ & 0.869 & 2.309 & 2.731 & 109.94
\end{tabular}

${ }^{a} \mathrm{D}$ and $\mathrm{A}$ stand for $\mathrm{H}$-donor and $\mathrm{H}$-acceptor, respectively. Bold elements belong to L-menthol.

already been published. The corresponding space groups are $\mathrm{P} 3_{1}$ trigonal and $\mathrm{P} 2{ }_{1} / \mathrm{C}$ monoclinic, respectively. The $\mathrm{CIF}$ documents resulting from the $\mathrm{X}$-ray experiments performed on cocrystal and on pure lidocaine and L-menthol were examined regarding bond lengths, angles, and torsion angles (see the Supporting Information). The conformational organization of the lidocaine and L-menthol molecules within the cocrystal may be said to be not significantly different compared to their organization within the lidocaine or L-menthol crystals. The pure lidocaine crystal is made up of a dimeric asymmetric unit, but within the cocrystal, the lidocaine asymmetric unit becomes monomeric. As far as the L-menthol crystal is concerned, its trimeric motif turns into a monomeric motif in the cocrystal.

As indicated in Figure 2B and compared to the pure lidocaine structure, ${ }^{23}$ the intramolecular hydrogen bonds resulting from the trans-amide configuration (chelate form) of the lidocaine are conserved in the cocrystal structure, with a slight increase of the $\mathrm{N}-\mathrm{H} \cdots \mathrm{N}$ hydrogen-bond length and angle: 2.24 to $2.31 \AA$ and 110.0 to $112.3^{\circ}$, respectively (Table 2). The related decrease of the intramolecular hydrogen-bond interactions in the cocrystal is balanced by the presence of two intermolecular hydrogen-bond types. Indeed, the $\mathrm{O}-\mathrm{H} \cdots \mathrm{O}$ one-cohesion interaction between two alcohol residues in the L-menthol network-which accounts for the stability of the crystalline edifice-is replaced in cocrystal by the $\mathrm{O}-\mathrm{H} \cdots \mathrm{O}$ and $\mathrm{N}-\mathrm{H} \cdots \mathrm{O}$ types between $\mathrm{L}-\mathrm{menthol}$ and lidocaine residues. These hydrogen bonds have longer lengths and smaller angles compared to the former intermolecular $\mathrm{O}-\mathrm{H} \cdots \mathrm{O}$ hydrogen bond in pure L-menthol. ${ }^{22}$

The thermodynamic data of the 1:1 compound were determined from DSC results. A congruent melting behavior was identified with a melting point at $39.1 \pm 0.2{ }^{\circ} \mathrm{C}$ and an enthalpy of fusion of $98.0 \pm 0.8 \mathrm{~J} \cdot \mathrm{g}^{-1}$ (i.e., $38.3 \mathrm{~kJ} / \mathrm{mol}$ of cocrystal or $19.2 \mathrm{~kJ} / \mathrm{mol}$ of lidocaine). To sum up, the lidocaine, L-menthol, and 1:1 compound experimental thermodynamic data are gathered in Table 3.

2. Lidocaine/L-Menthol Stable Phase Diagram. DSC experiments performed with the mixed solids (stoichiometric compound with L-menthol or lidocaine) lead to signals of the heat flow vs temperature as presented in Figure 4. The results exhibit two distinguishable tendencies between thermograms
TABLE 3: Experimental Temperatures and Enthalpies of Fusion for the Pure Components and the Cocrystal

\begin{tabular}{lcc}
\hline & $T_{\text {fus }}\left({ }^{\circ} \mathrm{C}\right)$ & $\Delta_{\text {fus }} H\left(\mathrm{~kJ} \cdot \mathrm{mol}^{-1}\right)$ \\
\hline 1:1 compound & $39.1 \pm 0.2$ & $38.3 \pm 0.3$ \\
L-menthol & $42.9 \pm 0.3$ & $14.1 \pm 0.2$ \\
lidocaine & $68.6 \pm 0.5$ & $16.9 \pm 0.2$
\end{tabular}

obtained for lidocaine molar ratio before and after the equimolar composition (Figure 4), leading to the phase diagram depicted in Figure 5. In this figure, the ideal liquidus calculated using the Schröder-van Laar relation ${ }^{24-26}$ (eq 1) has also been reported for comparison. One can observe a small deviation of the experimental phase diagram from the ideal one especially in the lidocaine-rich part of the diagram.

$$
\frac{\Delta_{\text {fus }} H}{R} \cdot\left(\frac{1}{T_{\text {fus }}}-\frac{1}{T_{x}}\right)=\ln (X)
$$

with $X=x$ for the liquidus obtained from L-menthol and from lidocaine. $X=4 x \cdot(1-x)$ for the two liquidi obtained from the equimolar compound. ${ }^{27} x$ stands for the molar ratio of one of the pure components, and $T_{x}$, the liquidus temperature of the corresponding mixture. $\Delta_{\text {fus }} H$ and $T_{\text {fus }}$ are, respectively, the enthalpy and the temperature of fusion of either the pure compounds

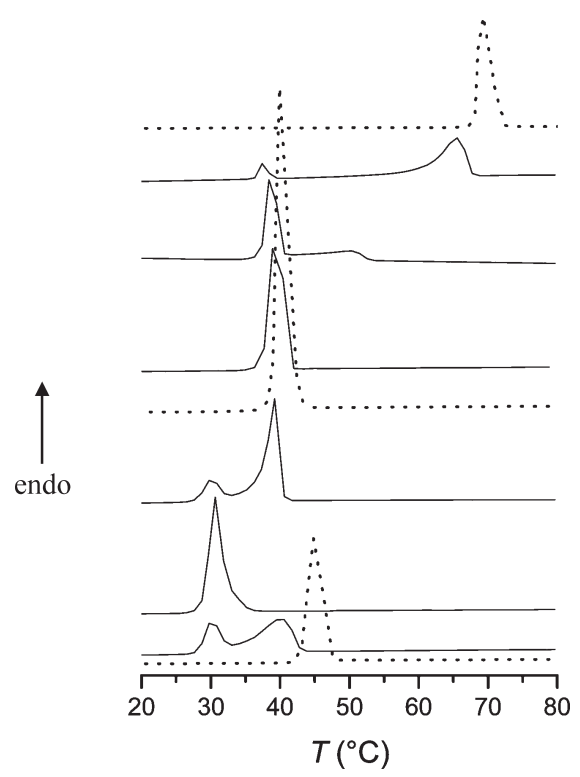

Figure 4. Weight-normalized DSC thermograms of lidocaine/L-menthol mixtures. Lidocaine molar ratios: $0.00,0.05,0.20,0.45,0.50,0.54$, $0.75,0.95$, and 1.00 from the bottom to the top curves, respectively. The thermograms were shifted for clarity. The dotted lines correspond to the thermograms of the pure compounds and the 1:1 compound. Endothermic transformations give signals pointing up. 


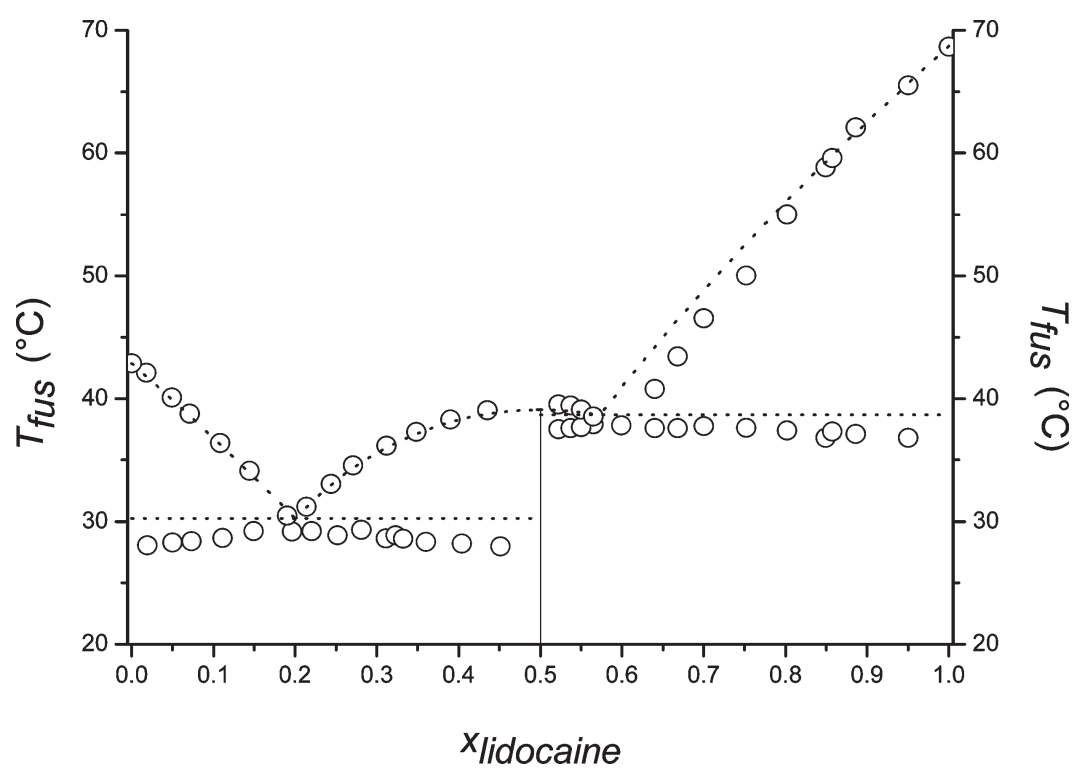

Figure 5. Temperature-composition solid-liquid equilibrium diagram of the lidocaine/L-menthol binary system. The experimental (open circles) and ideal behavior (dotted line) are shown.

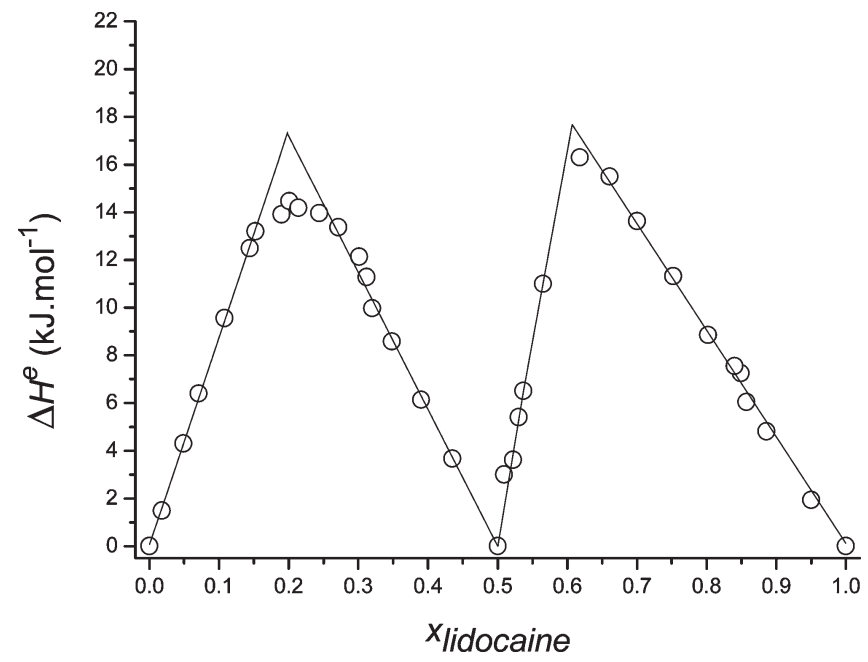

Figure 6. Tammann plots related to the eutectic equilibrium phase diagram of the lidocaine/L-menthol binary system.

or the cocrystal. $R$ is the gas constant. The temperatures are in kelvin.

The $T-x$ phase diagram confirms that the stoichiometric compound presents a congruent melting. On either side of the equimolar composition, two eutectic invariants are formed with lidocaine and L-menthol. X-ray powder diffraction experiments have shown that no solid solution is formed for enriched lidocaine or L-menthol solid mixtures (see the Supporting Information).

The Tammann plots (Figure 6) allowed determining the temperature and composition of the eutectic points: $x_{\mathrm{e}, 1}, 0.20$; $T_{\mathrm{e}, 1}, 28.6{ }^{\circ} \mathrm{C} ; x_{\mathrm{e}, 2}, 0.61 ; T_{\mathrm{e}, 2}, 37.6{ }^{\circ} \mathrm{C}$. These plots also confirm that no miscibility is encountered between cocrystal and L-menthol or lidocaine, since the straight lines intercept $\Delta H^{\mathrm{e}}=$ 0 at $x=0, x=0.5$, and $x=1$.

The 1:1 compound exhibits a complete dissociation in the liquid state and follows the ideal associated solution model. ${ }^{28}$ Indeed, the region of the $T-x$ diagram between the two eutectic points obeys eq $2 .{ }^{27}$

$$
\frac{\Delta_{\text {fus }} H}{R} \cdot\left(\frac{1}{T}-\frac{1}{T_{\mathrm{C}}}\right)=-\ln \left[(x)^{i} \cdot(1-x)^{j}\right]+\ln \left[\left(x_{\mathrm{C}}\right)^{i} \cdot\left(1-x_{\mathrm{C}}\right)^{j}\right]
$$

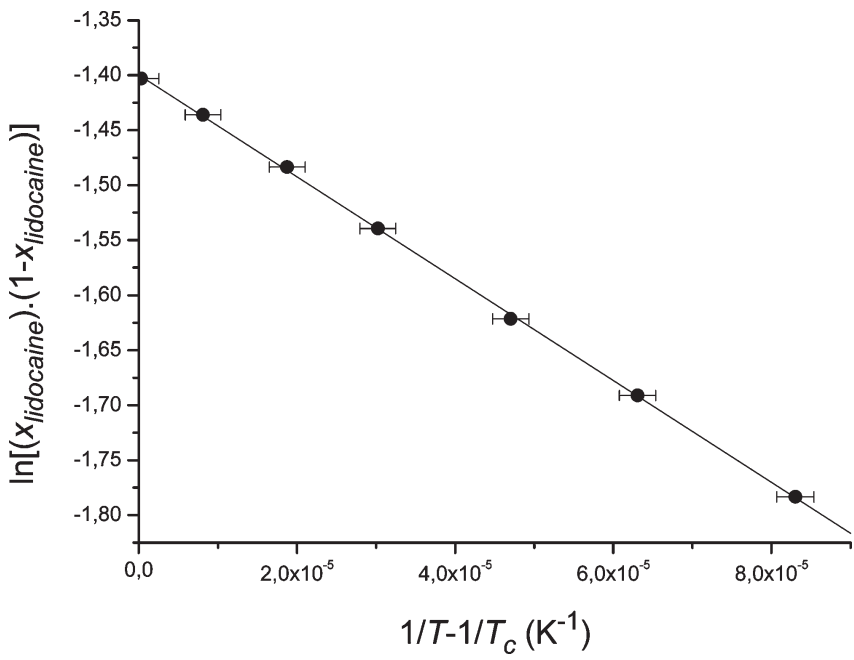

Figure 7. Plot related to eq $1: \ln [x(x-1)]$ against $\left(1 / T-1 / T_{\mathrm{C}}\right)$.

where $x$ corresponds to the molar ratio of a constituent, $\Delta_{\text {fus }} H$ the enthalpy of fusion, $T$ the temperature in kelvin, and $R$ the gas constant. $i$ and $j$ are the stoichiometric coefficients of the $i: j$ compound. The subscript $\mathrm{C}$ refers to the quantities at the congruent melting point with $T_{\mathrm{C}}=39.1{ }^{\circ} \mathrm{C}$ (from the DSC experiments).

Besides, the plot $\ln [x(x-1)]$ vs $\left(1 / T-1 / T_{\mathrm{C}}\right)$ is a straight line (Figure 7). It comes from the $\left(\left(1 / T-1 / T_{\mathrm{C}}\right)=0\right)$-intercept that $\ln \left[\left(x_{\mathrm{C}}\right)^{i}\left(1-x_{C}\right)^{j}\right]$ is equal to -1.39 , which gives a value of 0.50 for $x_{\mathrm{C}}$. This result confirms the formation of the $1: 1$ lidocaine:L-menthol compound. The slope of the straight line $\left(-\Delta_{\text {fus }} H / R\right)$ is equal to $-4.63 \times 10^{3} \pm 0.03 \times 10^{3} \mathrm{~K}$. This leads to an enthalpy of fusion of the 1:1 compound equal to 38.5 $\mathrm{kJ} \cdot \mathrm{mol}^{-1}$, with an error of $1.1 \mathrm{~kJ} \cdot \mathrm{mol}^{-1}$ estimated from the linear regression, in agreement with the experimental result (Table 3).

It is noteworthy that, when direct contact between lidocaine and L-menthol or between L-menthol and the 1:1 compound occurs at room temperature, molten mixtures are observed. The thus-obtained liquids do not systematically recrystallize, even by the thaw-melt method. ${ }^{29}$ These remarks are in accordance with Kang et al.'s observations concerning the two-year stability of the homogeneous oil phase at $25{ }^{\circ} \mathrm{C}$ systems in the lidocaine 
A

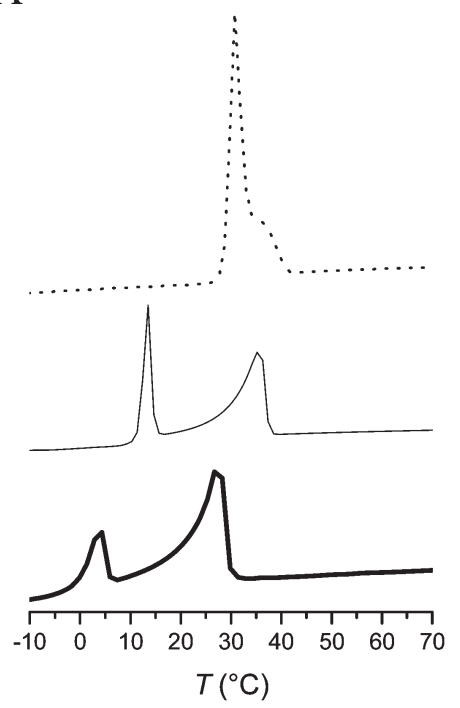

B

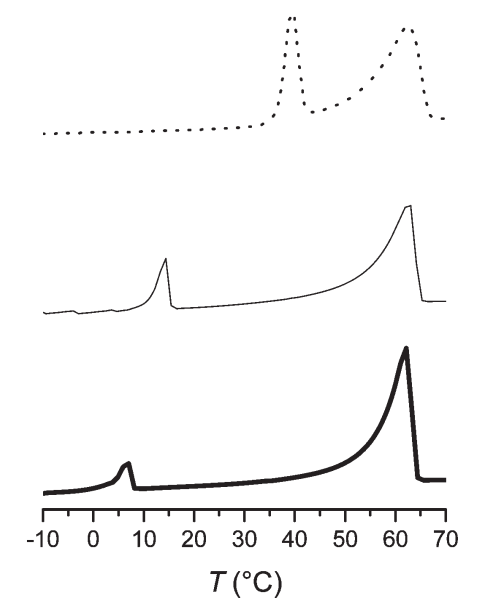

Figure 8. Thermograms of lidocaine/L-menthol mixtures recorded on heating the in situ recrystallized samples (bold solid line) and the recrystallized samples by annealing (thin solid line). For comparison, the thermograms related to the stable phase diagram are represented by dotted lines. $x_{\text {lidocaine: }}$ : (A) 0.11 ; (B) 0.89. Endothermic transformations give signals pointing up.

molar ratio range of $0.23-0.42 .{ }^{11}$ Such observations are not supported by the stable phase diagram. Therefore, a new phase diagram between lidocaine and L-menthol has to be considered.

3. Lidocaine/L-Menthol Metastable Phase Diagrams. When cocrystal is not formed, DSC experiments, performed from mixtures in the molten state, lead to different thermograms (Figure 8) that can be assigned to eutectic invariants (Figure 9A) with lower temperatures than those encountered for the stable diagram: 0.3 and $12.3{ }^{\circ} \mathrm{C}$.

The same solid-liquid equilibrium (liquidus curve) is observed for the lidocaine-rich part of the two eutectic diagrams (Figure 8A). This result indicates a unique transition point (fusion) for lidocaine. On the contrary, in the L-menthol-rich part of the diagram, the two distinct liquidi noticed have, as a consequence, to consider two transition points for L-menthol. The higher liquidus curve intercepts the temperature axis at the $\alpha$ L-menthol melting point. By using the same approach, the lower liquidus curve argues the fusion of the metastable phase of L-menthol (named the $\beta$-phase) estimated at $35.7{ }^{\circ} \mathrm{C}$. This result is in good agreement with previous studies. ${ }^{30}$ Afterward, by means of the Schröder-van Laar relation (eq 1), the enthalpy of fusion of the $\beta$ L-menthol has been estimated to be $71.5 \pm$ $1.5 \mathrm{~J} \cdot \mathrm{g}^{-1}\left(11.2 \mathrm{~kJ} \cdot \mathrm{mol}^{-1}\right)$.

The Tammann plots (Figure 9B) related to these metastable phase diagrams, involving the $\alpha$ - and $\beta$-phase of L-menthol, lead to temperatures and compositions of the eutectic points, respectively, equal to $x_{\mathrm{e}, \alpha}=0.37, T_{\mathrm{e}, \alpha}=12.3{ }^{\circ} \mathrm{C}$ and $x_{\mathrm{e}, \beta}=$ $0.35, T_{\mathrm{e}, \beta}=0.3{ }^{\circ} \mathrm{C}$. Since the straight lines of the Tammann plots intercept $\Delta H^{\mathrm{e}}=0$ at $x=0$ and $x=1$ for the two diagrams, it can be concluded that there is no miscibility in the solid state between L-menthol and lidocaine. Referring to the diagram proposed herein, we can suppose that lidocaine may induce a switch of the L-menthol conformation from the chair ( $\alpha$ form) to a less stable form: the $\beta$-phase.

It is interesting to point out that, upon heating, metastable systems may transform to stable ones (Figure 10). Nevertheless, as may be expected, the closer to 0.5 the lidocaine composition, the higher the probability of reforming the stable eutectic system.

4. Relative Stability of the Phase Diagrams from a Thermodynamic Point of View. The thermodynamic analysis of the three $T-x$ phase diagrams was conducted by determining
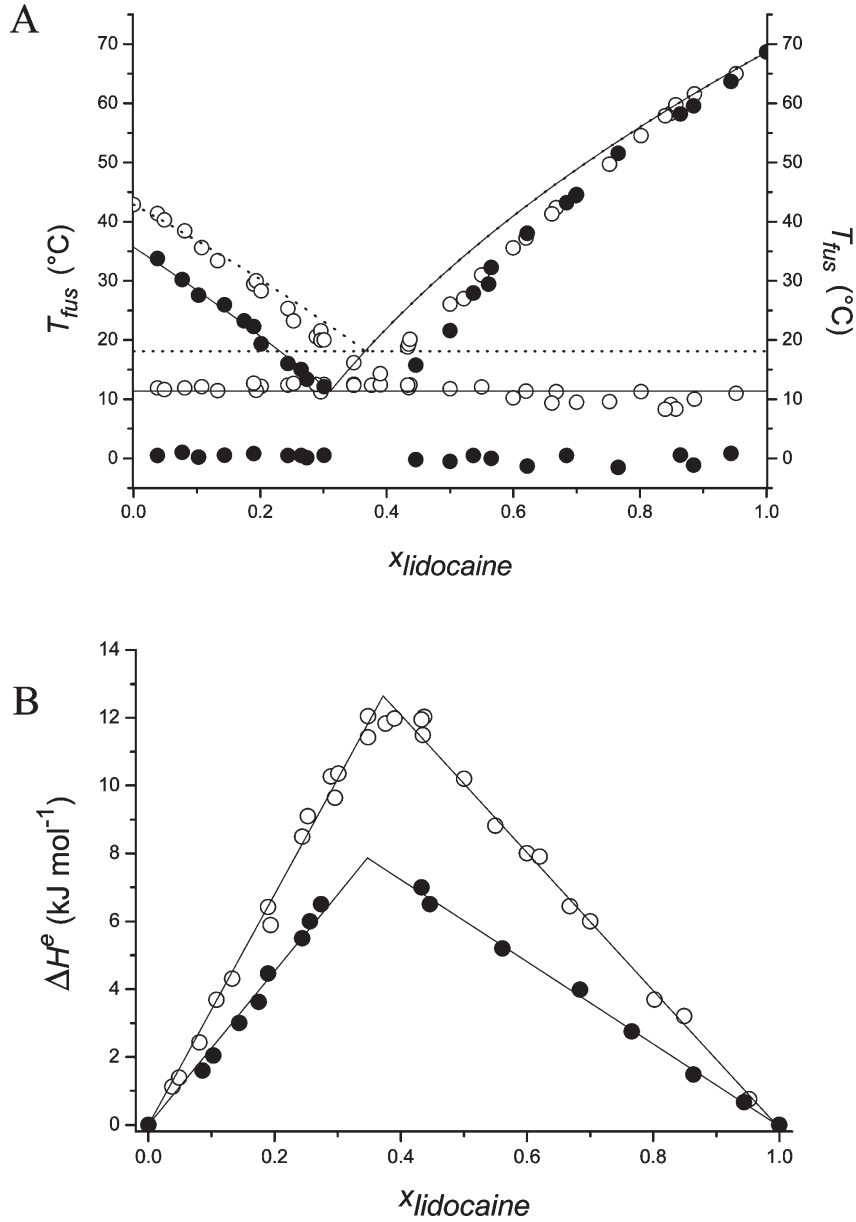

Figure 9. (A) Temperature-composition solid-liquid metastable phase diagram of the lidocaine/L-menthol binary system. The experimental (circles) and ideal behavior (lines) are shown. The data were collected from the one month annealed samples at $-5^{\circ} \mathrm{C}$ (open circles, dotted line) and from the in situ recrystallized samples between -80 and $-2{ }^{\circ} \mathrm{C}$ (filled circles, solid line). The corresponding Tammann plots are given in part $\mathrm{B}$.

the thermodynamic excess quantities in the liquid state for each eutectic composition at the eutectic temperature. Depression between experimental and theoretical eutectic temperatures $(\Delta T$ 
A

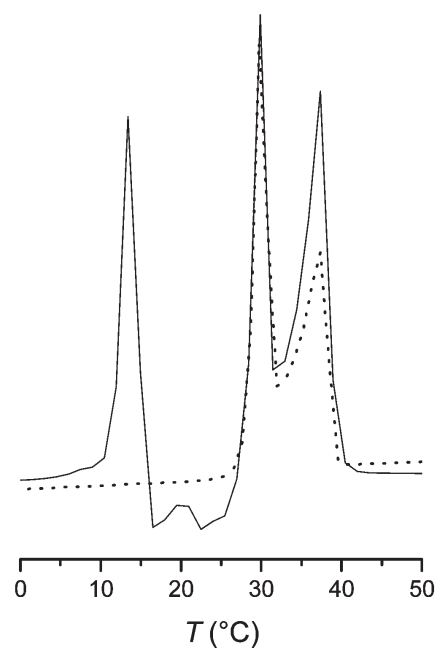

B

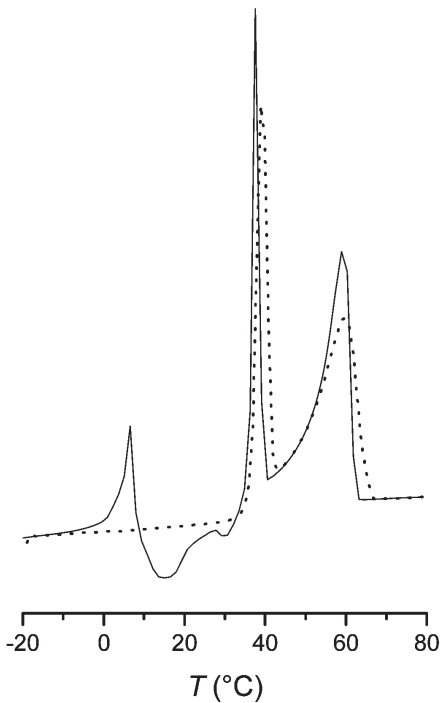

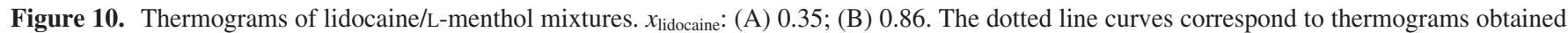
with the stable system. Endothermic transformations give signals pointing up.

TABLE 4: Thermodynamic Excess Quantities of the Liquid State for the Lidocaine/L-Menthol Binary Systems Calculated at the Eutectic Points

\begin{tabular}{|c|c|c|c|c|c|c|c|c|}
\hline \multirow[b]{2}{*}{ diagram type } & \multicolumn{2}{|c|}{ experimental data } & \multicolumn{2}{|c|}{ ideal data } & \multirow[b]{2}{*}{$\Delta T\left({ }^{\circ} \mathrm{C}\right)$} & \multirow[b]{2}{*}{$H_{\text {excess }}^{\text {liquid }}\left(\mathrm{J} \cdot \mathrm{mol}^{-1}\right)$} & \multirow[b]{2}{*}{$G_{\text {excess }}^{\text {liquid }}\left(\mathrm{J} \cdot \mathrm{mol}^{-1}\right)$} & \multirow[b]{2}{*}{$S_{\text {excess }}^{\text {liquid }}\left(\mathrm{J} \cdot \mathrm{mol}^{-1} \cdot \mathrm{K}^{-1}\right)$} \\
\hline & $x_{\mathrm{e}}$ & $T_{\mathrm{e}}\left({ }^{\circ} \mathrm{C}\right)$ & $x_{\mathrm{e}}$ & $T_{\mathrm{e}}\left({ }^{\circ} \mathrm{C}\right)$ & & & & \\
\hline stable & 0.20 & 28.6 & 0.20 & 30.2 & -1.6 & -400 & -430 & $\sim 0$ \\
\hline metastable $\alpha$ & 0.37 & 12.3 & 0.37 & 18.1 & -5.8 & -2500 & -350 & -8 \\
\hline metastable $\beta$ & 0.35 & 0.3 & 0.31 & 11.3 & -11.0 & -5300 & -310 & -18 \\
\hline
\end{tabular}

$\left.=T_{\exp }-T_{\text {ideal }}\right)$ is the result of supplementary intermolecular interactions in the liquid state (nonideal system). As no solid solutions had been noticed, no excess enthalpy in the solid state was considered $\left(\Delta H_{\text {excess }}^{\text {eutectic }}=H_{\text {excess }}^{\text {liquid }}-H_{\text {excess }}^{\text {solid }}=H_{\text {excess }}^{\text {liquid }}\right)$, and assuming the additivity of the specific heats in the solid state, ${ }^{31}$ the excess enthalpy at the eutectic point was determined, for each phase diagram, using the following expression:

$$
\begin{array}{r}
\Delta H_{\text {excess }}^{\text {eutectic }}=H_{\text {excess }}^{\text {liquid }}=\Delta_{\text {fus }} H^{\text {eutectic }}-\left(x_{\mathrm{A}}^{\text {eutectic }} \cdot \Delta_{\text {fus }} H_{\mathrm{A}}+\right. \\
\left.\left(1-x_{\mathrm{A}}^{\text {eutectic }}\right) \cdot \Delta_{\text {fus }} H_{\mathrm{B}}\right)
\end{array}
$$

with $\mathrm{A}$ and $\mathrm{B}$ being the pure compounds, $x_{\mathrm{A}}^{\text {eutectic }}$ the eutectic molar ratio of $\mathrm{A}$ in the $\mathrm{AB}$ mixture, and $\Delta_{\text {fus }} H$ the enthalpy of fusion of compound $\mathrm{A}, \mathrm{B}$, or the eutectic point.

The corresponding data are collected in Table 4. As expected, the $\left|H_{\text {excess }}^{\text {liquid }}\right|$ values increase with $|\Delta T|$, confirming a lighter deviation from ideal behavior for the stable diagram. Besides, a proportional relation between $\left|H_{\text {excess }}^{\text {liquid }}\right|$ and $|\Delta T|$ can be underlined. This goes along with the fact that the lower the melting entropy of the pure substances, the larger the depression of the freezing point. ${ }^{32}$

The excess Gibbs energy of the liquid phase ( $\left.G_{\text {excess }}^{\text {liquid }}\right)$ was then calculated at the eutectic point, using the EXTXD method. ${ }^{33}$ Consequently, the excess entropy was estimated from $G_{\text {excess }}^{\text {liquid }}=$ $H_{\text {excess }}^{\text {iquid }}-T_{\mathrm{e}} \cdot S_{\text {excess }}^{\text {liquid }}$ (Table 4 ), where $T_{\mathrm{e}}$ is the eutectic temperature.

For the stable phase diagram, it is interesting to notice that the excess entropy at the eutectic points is close to zero, while for the $\alpha$ and $\beta$ metastable diagrams, this quantity reaches -8 and $-18 \mathrm{~J} \cdot \mathrm{mol}^{-1} \cdot \mathrm{K}^{-1}$, respectively. These results confirm the greater relative stability of the phase diagram involving the addition compound.

\section{Conclusion}

Circumspect investigations of thermodynamic phase equilibrium are necessary at pharmaceutical scale in order to determine the ideal condition of preparation, use, and storage of active principal ingredients in their given state. Such research is also worthy for topical creams such as lidocaine based mixtures. Indeed, we ascertained that the previously reported lidocaine/ L-menthol temperature-composition phase diagram was not the stable one. A new cocrystal between lidocaine and L-menthol was discovered. The formation of cocrystals can be predicted using general rules as hydrogen bond rules, ${ }^{34,35}$ but most of the time, they are discovered empirically. ${ }^{36}$ Preparing mixtures using the new compound was finally the only way to obtain the lidocaine/L-menthol stable phase diagram which has proved to be a congruent melting type diagram with two distinguishable eutectic points on either side of the equimolar composition. As far as the two metastable phase diagrams are concerned, one is obtained from lidocaine/L-menthol in the respective stable phase and the other one from an L-menthol polymorph which may be induced by the lidocaine/L-menthol interactions. As metastable systems may transform into stable ones, this paper presents an overview of phase diagram ambiguities. All of the results gathered highlight the benefit of determining a stable phase diagram in order to prevent from its misunderstanding while collecting data for a metastable diagram. In a pharmaceutical field where deep eutectics might be promising inasmuch as they yield to liquid mixtures, our work reveals that these systems need to be well-defined from a thermodynamic perspective in order to avoid interpretation of metastable properties. This work demonstrates that it is vital to conduct physical chemistry studies before the formulation, patenting, and/or commercialization of the metastable form of pharmaceutical agents. Conditions such as temperature, pressure, ${ }^{37}$ or chemical environment ${ }^{38}$ could 
enhance the formation of the cocrystal which corresponds to the thermodynamically most stable state of the binary system. ${ }^{39}$

Acknowledgment. We thank Denise McDonald-Dampierre and Geneviève Arnaud-Vincent for fruitful discussions and advice on the manuscript.

Supporting Information Available: X-ray crystallographic information file (CIF) for lidocaine:L-menthol cocrystals and $\mathrm{X}$-ray powder diffraction patterns. This material is available free of charge via the Internet at http://pubs.acs.org.

\section{References and Notes}

(1) Robieux, I.; Eliopoulos, C.; Hwang, P.; Greenberg, M.; Blanchette, V.; Olivieri, N.; Klein, N.; Koren, G. Pediatr. Res. 1992, 32, 520-523.

(2) Buckley, M. M.; Benfield, P. Drugs 1993, 46, 126-151.

(3) Kang, L.; Jun, H. W.; Mani, N. Int. J. Pharm. 2001, 222, 35-44.

(4) Kang, L.; Jun, H. W. Drug Dev. Ind. Pharm. 2003, 29, 505-512.

(5) Lazerges, M.; Rietveld, I. B.; Corvis, Y.; Ceolin, R.; Espeau, P. Thermochim. Acta 2010, 497, 124-128.

(6) Frey, B.; Kehrer, B. Eur. J. Pediatr. 1999, 158, 785-788.

(7) Touma, S.; Jackson, J. B. J. Am. Acad. Dermatol. 2001, 44, 399400.

(8) Abu Hena Mostofa Kamal, M ; Iimura, N.; Nabekura, T.; Kitagawa, S. Chem. Pharm. Bull. 2006, 54, 481-484.

(9) Tokuoka, Y.; Suzuki, M.; Ohsawa, Y.; Ochiai, A.; Ishizuka, M.; Kawashima, N. Drug Dev. Ind. Pharm. 2008, 34, 595-601.

(10) Jun, H. W.; Kang, L. Enhanced transdermal anesthesia of local anesthetic agents. PCT Int. Appl. WO 6299902 B1, 2001.

(11) Kang, L.; Jun, H. W.; McCall, J. W. Int. J. Pharm. 2000, 206, $35-42$.

(12) Trask, A. V.; van de Streek, J.; Motherwell, W. D. S.; Jones, W. Cryst. Growth Des. 2005, 5, 2233-2241.

(13) Jones, W.; Motherwell, W. D. S.; Trask, A. V. MRS Bull. 2006, $31,875-879$

(14) Stahly, G. P. Cryst. Growth Des. 2009, 9, 4212-4229.
(15) Good, D. J.; Rodriguez-Hornedo, N. Cryst. Growth Des. 2009, 9, 2252-2264.

(16) Mercury 2.2; http://www.ccdc.cam.ac.uk/products/mercury (accessed March, 2010).

(17) Materials Studio Modeling 4.2; http://accelrys.com/products/ materials-studio (accessed March, 2010).

(18) Farrugia, L. J. J. Appl. Crystallogr. 1997, 30, 565.

(19) Sheldrick, G. M.; Kröger, C.; Goddard, R. SHELX 86 in Crystallographic Computing 3; Oxford University Press: New York, 1985; pp 175189.

(20) Sheldrick, G. M. SHELX 97, Program for the Refinement of the Crystal Structures; University of Göttingen: Göttingen, Germany, 1997.

(21) Espeau, P.; Ceolin, R. Thermochim. Acta 2001, 376, 147-154.

(22) Bombicz, P.; Buschmann, J.; Luger, P.; Dung, N. X.; Nam, C. B. Z. Kristallogr. 1999, 214, 420-423.

(23) Bambagiotti-Alberti, M.; Bruni, B.; Di Vaira, M.; Giannellini, V.; Guerri, A. Acta Crystallogr., Sect. E 2007, E63, o768-o770.

(24) Schröder, I. Z. Phys. Chem. 1893, 11, 449.

(25) Van Laar, J. J. Arch. Neerl. 1903, 8, 264-284.

(26) Le Chatelier, H. C. R. Acad. Sci. 1894, 118, 638.

(27) Prigogine, I.; Defay, R. Thermodynamique chimique, Tome II; Dunod: Paris, 1946; pp 294-295.

(28) Rastogi, R. P.; Nigam, R. K. J. Phys. Chem. 1960, 64, 722-726.

(29) Janz, G. J.; Donnelly, T. H. Anal. Chem. 1952, 24, 1045-1046.

(30) Wright, F. E. J. Am. Chem. Soc. 1917, 39, 1515-1524.

(31) Bros, J. P.; Gaune-Escard, M. Rev. Phys. Appl. 1979, 14, $107-$ 112.

(32) Oonk, H. A. J.; Calvet, M. T. Equilibrium between phases of matter; Springer: The Netherlands, 2008.

(33) Brouwer, N.; Oonk, H. A. J. Z. Phys. Chem. 1979, 117, 55-67.

(34) Etter, M. C. Acc. Chem. Res. 1990, 23, 120-126.

(35) Etter, M. C. J. Phys. Chem. 1991, 95, 4601-4610.

(36) Stahly, G. P. Cryst. Growth Des. 2007, 7, 1007-1026.

(37) Oswald, I. D. H.; Pulham, C. R. CrystEngComm 2008, 10, 1114 1116

(38) Jayasankar, A.; Somwangthanaroj, A.; Shao, Z. J.; RodriguezHornedo, N. Pharm. Res. 2006, 23, 2381-2392.

(39) Trask, A. V. Mol. Pharmaceutics 2007, 4, 301-309. 